\title{
A ADOÇÃO DA APRENDIZAGEM COOPERATIVA (AC) COMO PRÁTICA PEDAGÓGICA NA EDUCAÇÃO AMBIENTAL (EA): POSSIBILIDADES PARA O ENSINO $E$ A APRENDIZAGEM DE CONTEÚDOS CONCEITUAIS, PROCEDIMENTAIS E ATITUDINAIS.
}

\author{
Job Antonio Garcia Ribeiro ${ }^{1}$ \\ Osmar Cavassan ${ }^{2}$
}

\section{Resumo:}

Este estudo teórico apresenta e discute as demandas educacionais hodiernas, problematizando a fragilização de ações pedagógicas que não alcançam os objetivos propostos pela Educação Ambiental (EA). Ao abordar a tipologia de conteúdos e relacionar os conhecimentos conceituais, procedimentais e atitudinais com as diversas correntes ambientais, busca refletir sobre a promoção da competência ambiental e seus elementos constituintes. Defende que mudanças na estrutura de aprendizagem e nas variáveis que determinam a ação docente, quando concatenadas com uma prática educativa fundamentada na Aprendizagem Cooperativa (AC), podem contribuir para a ampliação do meio ambiente individual, ao promover o diálogo de saberes em grupos cooperativos.

Palavras-chave: Competência ambiental. Grupos de aprendizagem cooperativa. Meio ambiente.

\section{ADOPTING COOPERATIVE LEARNING (CL) AS A PEDAGOGICAL PRACTICE IN ENVIRONMENTAL EDUCATION (EE): POSSIBILITIES FOR THE TEACHING AND LEARNING OF CONCEPTUAL, PROCEDURAL AND ATTITUDINAL CONTENTS}

\begin{abstract}
:
This theoretical study presents and discusses today's educational demands, questioning weak pedagogical actions that do not achieve the objectives proposed by Environmental Education (EE). On approaching types of contents and relating conceptual, procedural, and attitudinal knowledge to several environmental trends, it aims to reflect on how to foster environmental competence and its constituent elements. It advocates that changes in the learning structure and in the variables that determine teachers' actions, when linked to an educational practice based on Cooperative Learning (CL), may contribute to broaden the individual's environmental, encouraging the exchange of knowledge in cooperative groups.
\end{abstract}

Keywords: Environmental competence. Groups of cooperative learning. Environment.

LA ADOPCIÓN DEL APRENDIZAJE COOPERATIVO (AC) COMO PRÁCTICA PEDAGÓGICA EN LA EDUCACIÓN AMBIENTAL (EA): POSIBILIDADES PARA LA ENSEÑANZA Y EL APRENDIZAJE DE CONTENIDOS CONCEPTUALES, PROCEDIMENTALES Y ACTITUDINALES.

\footnotetext{
${ }^{1}$ Doutorando em Educação para a Ciência. Programa de Pós-graduação em Educação para a Ciência, Faculdade de Ciências, Universidade Estadual Paulista "Júlio de Mesquita Filho", UNESP, Câmpus de Bauru - SP. job_ribeiro2005@yahoo.com.br

2 Programa de Pós-graduação em Educação para a Ciência, Faculdade de Ciências, Universidade Estadual Paulista "Júlio de Mesquita Filho", UNESP, Câmpus de Bauru - SP. cavassan@fc.unesp.br
} 


\section{Resumen}

Este estudio teórico presenta y discute las demandas de educación actuales, cuestionando la fragilización de las acciones pedagógicas que no alcanzan los objetivos propuestos por la Educación Ambiental (EA). Al abordar el tipo de contenido y relacionar los conocimientos conceptuales, procedimentales y actitudinales con las diversas corrientes ambientales, se busca reflexionar sobre la promoción de la competencia ambiental y sus elementos constitutivos. Argumenta que los cambios en la estructura de aprendizaje y las variables que determinan la acción docente, al concatenarse con una práctica educativa basada en el aprendizaje cooperativo (AC), pueden contribuir a la expansión del entorno, al promover el diálogo de saberes en grupos cooperativos.

Palabras-clave: Competencia ambiental. Grupos de aprendizaje cooperativo. Medio ambiente.

\section{Introdução}

A educação de cada período é vista como pertinente e adequada ao seu tempo, pois toda época tem uma educação que procura atender às necessidades próprias de seu contexto histórico. No entanto, deixam de ser à medida que novas exigências vão se impondo no cenário da vida social (NÉRICI, 1970; ALVAREZ; DEL RÍO, 1996).

As diferentes e, por vezes, conflitantes concepções educativas são ditadas pelos contextos de cada momento; pelas exigências sociais de produção, distribuição e consumo; pelos ideais sociopolíticos, teóricos e filosóficos de modelo social e pelo conhecimento do mundo e do homem. Todavia, no decorrer do tempo, surge a necessidade de considerar outras demandas, novos princípios de ação, buscar um novo paradigma, outras formas de trabalho e pensar em novas possibilidades metodológicas (KRASILCHIK, 2000; POZO; CRESPO, 2009).

A partir da década de 1990, por exemplo, a comunidade científica e educacional passou a ter, como uma de suas metas, um ensino capaz de permitir aos estudantes o desenvolvimento de um pensar lógico e de um agir crítico. O próprio conceito de ensino modificou-se: de uma visão mais próxima de instrução para uma concepção relacionada ao desenvolvimento da autonomia dos indivíduos e de suas capacidades (SANMARTÍ, 2002; POZO; CRESPO, 2009).

Nas instituições escolares, passamos a defender a necessidade de formar pessoas aptas a tomarem decisões fundamentadas, não somente por meio da aprendizagem de conteúdos científicos, mas também através do desenvolvimento de competências. A preparação para a vida pautada numa formação intelectual e afetiva para o desempenho consciente de nosso papel na sociedade, tornou-se uma das finalidades da escolarização (BRASIL, 1997, 2010; DELORS et al., 2010).

A escola é, agora, concebida como um recurso em direção à cidadania, uma cidadania capaz de favorecer a cooperação, a discussão e a resolução de problemas, ensinar conhecimentos e habilidades. Esses conteúdos são considerados fundamentais para o ser humano aprimorar sua qualidade de vida, tomar decisões e continuar a aprender (REIS, 2000; ZABALA; ARNAU, 2010; DELORS, et al., 2010).

Nessa perspectiva, educar implica atuar nos processos socializadores de indivíduos e grupos, desenvolvendo determinados atributos desejáveis. Em tal processo, que não afeta todos da mesma maneira, aprendemos habilidades e comportamentos, e até mesmo o que é definido como agradável e/ou desagradável (TASSARA; ARDANS, 2005). Isso significa 
dizer que "o processo educativo não se restringe ao aprendizado individualizado dos conteúdos escolares, mas se dá na relação de um indivíduo com o outro, de um indivíduo com o mundo" (GUIMARÃES, 2010, p.143).

No que se refere à Educação Ambiental (EA) é possível notar, também, uma preocupação em promover o desenvolvimento de valores e atitudes em prol de uma sociedade pautada por novos patamares civilizacionais (LOUREIRO, 2009; GUIMARÃES, 2010). Pressupostos que preconizam a democracia, o diálogo, o respeito e a cooperação mútua e equitativa nos processos de decisão, estão inseridos nas diversas propostas ambientais (BRASIL, 1999; SAUVÉ, 2005; TOZONI-REIS, 2008; CARVALHO, 2008; REIGOTA, 2009; PEDRINI; SAITO, 2014).

Entretanto, não podemos supor que essas demandas têm proporcionado, concomitantemente, mudanças significativas nas práticas docentes. Os discursos em prol da formação de estudantes mais comprometidos com os valores sociais e os princípios de solidariedade, parecem não garantir intervenções efetivas. Muitas práticas educativas fazem uso de modelos pedagógicos que não alcançam, concretamente, aquilo que nos discursos almejam: o desenvolvimento da responsabilidade individual e coletiva, a igualdade, o respeito e o diálogo democrático.

Há, por exemplo, o desejo de se efetuar uma EA emancipatória e crítica, articulada com o exercício da cidadania, mas ainda reproduzimos uma ideologia hegemônica que possui uma finalidade meramente conteudista e informativa. Apesar da difusão crescente, a EA apresenta-se fragilizada em suas ações pedagógicas, na medida em que elas não geram transformações significativas da realidade (GUIMARÃES, 2010), tampouco tem possibilitado a ampliação da percepção do meio ambiente. Nesse sentido, é fundamental um aperfeiçoamento de seus procedimentos metodológicos (PEDRINI; SAITO, 2014).

Se um dos pressupostos da EA e de seus diferentes matizes é possibilitar o ensino e a aprendizagem de conceitos, procedimentos e atitudes, como nós pesquisadores, professores e/ou educadores podemos concretizar essa máxima? De que maneira nossas intervenções podem colaborar com a socialização e a individuação do sujeito, de forma a favorecer a (re)construção ou ressignificação dos meios ambientes individuais? Como articular uma prática educativa onde haja coerência entre discurso e ação?

Essas reflexões orientam o presente trabalho, que busca apresentar elementos teóricos - problematizá-los, refletir sobre eles e entrelaçá-los - capazes de justificar a adoção da Aprendizagem Cooperativa (AC) como prática pedagógica ambiental. Objetivamos, também, defender a ideia de que essa ação propicia sínteses mais complexas e integrativas com relação aos aspectos que compõem o meio ambiente.

\section{A EA e os conteúdos conceituais, procedimentais e atitudinais constituintes da competência ambiental}

Entendida como os processos por meio dos quais o indivíduo e a coletividade constroem valores sociais, conhecimentos, habilidades, atitudes e competências voltadas para a conservação do meio ambiente (BRASIL, 1999), a EA tem como finalidade garantir certo nível de conhecimento, o desenvolvimento de determinadas atitudes e a promoção de certos valores.

Essa definição faz referência à tipologia de conteúdos adotada por Coll e colaboradores (2000), que é discutida nos trabalhos de Antoni Zabala (ZABALA; 1998; ZABALA; ARNAU, 2010) e está presente nos Parâmetros Curriculares Nacionais (BRASIL, 1997).

Ao fazerem uso de uma construção intelectual com a intenção de compreenderem os processos cognitivos e condutuais, e analisarem o que se dá de maneira integrada, Coll e 
colaboradores (2000) elaboraram uma categorização diferente daquela baseada nos conhecimentos das matérias. Para eles, existiriam três tipos de conteúdo: os conceituais, os procedimentais e os atitudinais. Qualquer objeto suscetível de aprendizagem (conteúdo) ou é conceitual, ou é procedimental ou é atitudinal.

Os conteúdos conceituais podem ser identificados por meio da seguinte questão: $o$ que se deve saber? São conteúdos ligados, predominantemente, às capacidades cognitivas, isto é, à nomes, conceitos, princípios, fatos, enunciados, teoremas, leis, acontecimentos, situações, fenômenos concretos e dados. Podemos identificá-los, por exemplo, quando selecionamos para um projeto, disciplina ou prática de EA, os conhecimentos a serem ensinados ou a lista de bibliografia que tratará dos conceitos e informações que julgamos ser as principais (sustentabilidade, Conferência de Belgrado, Ecossistema, meio ambiente, Agenda 21, comunidade etc.).

Já os conteúdos procedimentais dizem respeito às ações ou conjunto de ações ordenadas e dirigidas para a realização de um ou mais objetivos; estão relacionados ao domínio de uma destreza ou habilidade, ou seja, ao saber fazer (saber ler, observar, calcular, classificar, inferir, discutir, realizar um procedimento, uma técnica, elaborar uma estratégia etc.).

Por sua vez, os conteúdos atitudinais estão relacionados às capacidades afetivas e sociais; são valores, atitudes e normas que permitem às pessoas emitir um juízo ou exercer determinada conduta. Referem-se ao como se deve ser. É nessa categoria de conteúdo que encontramos expressões como: ser solidário, ser cooperativo, ser responsável, ser autônomo e ser atuante socialmente.

Cada tipologia de conteúdo - e isso é frequentemente desconsiderado - possui uma maneira mais adequada de se ensinar e requer atividades específicas capazes de promover sua aprendizagem. Conteúdos conceituais, como dados e fatos, podem ser aprendidos, principalmente, por meio de cópia e reprodução ou quando estão associados a conceitos; logo, atividades que fomentem a lembrança são essenciais. Conteúdos procedimentais associados à realização de ações são aprendidos não somente fazendo, mas também exercitando, refletindo sobre elas e aplicando-as à contextos diferenciados. Por fim, valores como o respeito e a cooperação (conteúdos atitudinais), podem ser aprendidos quando se cria situações específicas, como é o caso das relações comunicativas que ocorrem nos contextos educativos (ZABALA, 1998).

A utilização dessa tipologia não é uma questão puramente terminológica, tampouco representa uma desvalorização dos conteúdos tradicionais (COLL et al., 2000). Trata-se de uma reconsideração do papel de outras habilidades e outros conhecimentos na educação. A descrição aqui realizada não busca, apenas, chamar a atenção do leitor para essas categorias, mas também para a relação que podemos estabelecer entre a EA, seus objetivos e o desenvolvimento das competências.

$\mathrm{Na}$ literatura encontramos muitas definições para o conceito de competência, que são elaboradas a partir de diferentes instâncias. No contexto escolar, esse termo refere-se ao que qualquer pessoa necessita para responder aos problemas que enfrentará. Diz respeito à intervenção eficaz nos diferentes âmbitos da vida por meio de ações nas quais se mobilizam, ao mesmo tempo e de maneira inter-relacionada, componentes atitudinais, procedimentais e conceituais (ZABALA; ARNAU, 2010).

O ensino de competências tem como finalidade formar o ser humano em todas as suas capacidades, para que seja capaz de responder aos problemas que se apresentam. Cumpre uma função orientadora, a fim de permitir a cada um dos alunos o acesso aos meios para que possam se desenvolver conforme suas possiblidades, em todas as etapas da vida. Trata-se de um ensino que busca favorecer o desenvolvimento pessoal, interpessoal, social e profissional (BRASIL, 1997; ZABALA; ARNAU, 2010). 
Essa é uma concepção que vem ganhando espaço no ensino obrigatório, que recupera e ressignifica as ideias de autores escolanovistas como John Dewey (1859-1952), Jean-Ovide Decroly (1871-1932), William Heard Kilpatrick (1871-1965), Adolphe Ferrière (1879-1960), Célestin Freinet (1896-1966) e outros (KILPATRICK, 1973; IMBERNÓN, 2012). Educadores cujas ideias

[...] adquiriram um status oficial ao serem compartilhadas pela totalidade das instâncias internacionais que tem competência no campo da educação como a ONU, a UNESCO e a OCDE, e que consideram que a função da escola deve consistir na formação integral da pessoa, para que esta seja capaz de responder aos problemas que a vida propõe (ZABALA; ARNAU, 2010, p.23).

No documento elaborado pela Comissão Internacional sobre Educação para o século XXI, em 1996, notamos a importância dada às competências e aos seus processos de desenvolvimento. Esse relatório da UNESCO (Relatório Delors) defende que a educação deve acontecer ao longo da vida e se pautar em quatro pilares: aprender a conviver, aprender a ser, aprender a fazer e aprender a conhecer.

Numa sociedade da informação torna-se essencial desenvolver competências que permitam aos sujeitos selecionar, organizar e interpretar essas informações, dando-lhes sentido e permitindo sua assimilação crítica. Uma vez que não há saberes absolutos, os estudantes devem aprender a conviver com a diversidade de perspectivas, com a relatividade das teorias, com a existência de interpretações múltiplas, bem como, aprender a construir seu próprio julgamento ou ponto de vista a partir dessas informações (SANMARTÍ, 2000; ALARCÃO, 2007; DELORS et al., 2010).

No entanto, o ensino de competências ainda enfrenta dificuldades para superar a perspectiva propedêutica enraizada em nossa cultura (ZABALA; ARNAU, 2010). Isso se deve à compreensão limitada dos processos de ensino e de aprendizagem dos conteúdos conceituais, procedimentais e atitudinais, que compõem sua dimensão estruturante. Desconsidera-se que, para cada caso, existem estratégias didáticas, processos psicológicos, ações pedagógicas específicas e instrumentos mais apropriados. Acreditamos que no contexto da EA isso não é diferente; há um descompasso entre o que se pretende ensinar e as estratégias utilizadas, entre o discurso e a intervenção.

Ao considerarmos as distintas correntes ou vertentes metodológicas de EA (SAUVÉ, 2005; PEDRINI; SAITO, 2014), que resultam na construção de diferentes ações educativas, encontramos muitos elementos comuns entre elas, no que se refere às capacidades a serem desenvolvidas nos processos de ensino e de aprendizagem. Em termos de enfoques pedagógicos é possível identificar no trabalho de Sauvé (2005), por exemplo, seis perspectivas predominantes que representam, implícita ou explicitamente, os elementos estruturais das competências (quadro 01).

Quadro 01 - Categorização das perspectivas que fundamentam as correntes de EA de acordo com os conteúdos predominantes

\begin{tabular}{|c|c|c|}
\hline Perspectivas & $\begin{array}{l}\text { Elementos } \\
\text { predominantes }\end{array}$ & $\begin{array}{l}\text { Correntes de EA segundo Sauvé } \\
\text { (2005) }\end{array}$ \\
\hline Cognitiva & Conteúdos conceituais & $\begin{array}{l}\text { - Científica } \\
\text { - Sustentabilidade }\end{array}$ \\
\hline Sensório-motora & Conteúdos atitudinais & $\begin{array}{l}\text { - Humanista } \\
\text { - Holística } \\
\text { - Naturalista } \\
\text { - Ecoeducativa }\end{array}$ \\
\hline Comportamental & Conteúdos procedimentais & $\begin{array}{l}\text { - Conservacionista/recursista } \\
\text { - Resolutiva }\end{array}$ \\
\hline
\end{tabular}




\begin{tabular}{|l|l|l|}
\hline Ético-moral & Conteúdos atitudinais & - Sistêmica \\
\hline $\begin{array}{l}\text { Político- } \\
\text { participativa }\end{array}$ & $\begin{array}{l}\text { Conteúdos procedimentais } \\
\text { Conteúdos atitudinais }\end{array}$ & - Moral/ética \\
\hline Multicultural & Conteúdos atitudinais & - Práxica \\
\hline
\end{tabular}

$\mathrm{Na}$ primeira perspectiva (cognitiva) incluímos as correntes de EA que enfatizam os conhecimentos, principalmente aqueles relacionados aos conceitos, como é o caso das correntes científica e de sustentabilidade. Na perspectiva sensório-motora estão correntes como a humanista, a holística, a naturalista e a ecoeducação, que priorizam, fundamentalmente, o desenvolvimento de capacidades afetivas. A comportamental, por sua vez, dá um enfoque maior aos imperativos de ação, ou seja, ao desenvolvimento de determinadas habilidades (resolução de problemas, análise, síntese etc.) como, por exemplo, as correntes conservacionista/recursista, resolutiva e sistêmica.

A corrente moral/ética caracteriza a quarta perspectiva (ético-moral) e prioriza o desenvolvimento de valores individuais e coletivos. Na perspectiva político-participativa incluímos as correntes biorregionalista, práxica, de crítica social e feminista, uma vez que, enfatizam a necessidade de transformação de uma dada realidade, que se daria a partir do desenvolvimento de habilidades comunicativas e democráticas. Por fim, a perspectiva multicultural tem como representante a corrente etnográfica, caracterizada pela promoção e valorização das interações étnico-culturais.

O que pretendemos destacar com essa breve categorização é que todas essas perspectivas não são excludentes, são apenas distintas. Cada corrente prioriza o desenvolvimento de determinados conteúdos, o que não quer dizer que não contemplem os demais. Buscamos elementos comuns entre elas, sobreposições entre essas vertentes metodológicas, sem a intenção de descaracterizá-las ou dizer que são iguais. Elas são ideologicamente distintas, mas possuem em comum o fato de priorizarem, em seus discursos e práticas, um ou mais componentes estruturais das competências. Há, também, em todas elas uma preocupação com a promoção da transformação individual e do bem-estar da coletividade em prol da cidadania (PEDRINI; SAITO, 2014).

Essa afirmação pode ser verificada ao identificarmos, na literatura, as seguintes características a serem desenvolvidas e priorizadas pelas correntes de EA: ser participativo em prol da construção de uma sociedade democrática; ter responsabilidade individual e coletiva, compreendendo as relações de interdependência e realizando autorreflexões; desenvolver valores que permitam uma transformação social; promover e estimular a solidariedade, a igualdade e o respeito; facilitar a cooperação mútua e equitativa nos processos de decisão, valorizando as diferentes formas de conhecimento e respeitando as diferenças; estar apto para o diálogo e para o enfrentamento de conflitos, buscando alternativas aos problemas cotidianos e possibilitar uma convivência digna, voltada para o bem comum, fortalecendo a ação coletiva (BRASIL, 1999; TOZONI-REIS, 2008; CARVALHO, 2008; REIGOTA, 2009; LOUREIRO 2009; PEDRINI, SAITO, 2014).

Note que esses elementos a serem ensinados e aprendidos, embora não sejam descritos com a nomenclatura competência(s), fazem referência à tipologia de conteúdos e possuem clara preocupação com a formação de cidadãos autônomos, críticos e participativos, os quais: (1) exerçam de forma responsável e crítica a autonomia, a cooperação, a criatividade e a liberdade, por meio do conhecimento e da compreensão de si mesmos; (2) compreendam os demais, saibam dialogar, conviver, resolver conflitos, desenvolver a solidariedade e se relacionar; (3) sejam capazes de transformar a sociedade participando de sua gestão, tomando 
posições informadas, críticas e cooperadoras; (4) respeitem a diversidade cultural, os valores das diferentes civilizações e exercitem a democracia plena e a responsabilidade coletiva.

Essas capacidades, a nosso ver, são também essenciais para o processo de ampliação da percepção do meio ambiente, pois potencializam o processo de ressignificação ambiental, ou seja, permitem a recriação, a reinterpretação das informações, das representações, dos conceitos e significados. Em outras palavras, favorecem a construção de novas relações significativas e a ampliação de nossa visão de mundo. Esses componentes conceituais, procedimentais e atitudinais constituem, portanto, o que podemos denominar de competência ambiental (quadro 02). Tal competência é composta por elementos já presentes nos discursos de EA, mas que, muitas vezes, não são considerados objetos legitimados de ensino e de aprendizagem.

Quadro 02 - Elementos estruturantes da competência ambiental

\begin{tabular}{|l|l|}
\hline Conteúdos & Conhecimentos - objetos de ensino e de aprendizagem \\
\hline Conteúdos conceituais & $\begin{array}{l}\text { Conhecimentos curriculares do campo das Ciências Naturais e Sociais. } \\
\text { Conteúdos socialmente relevantes, selecionados de acordo com suas } \\
\text { potencialidades formativas. }\end{array}$ \\
\hline $\begin{array}{l}\text { Conteúdos } \\
\text { procedimentais }\end{array}$ & $\begin{array}{l}\text { Habilidades sociais e comunicativas que fundamentam as relações } \\
\text { interpessoais (saber dialogar, relacionar-se, conviver, partilhar informações, } \\
\text { cooperar, ouvir e reconsiderar ideias, saber respeitar e valorizar a } \\
\text { diversidade de perspectivas etc.) }\end{array}$ \\
\hline
\end{tabular}

Conteúdos atitudinais Respeito, cooperação, autonomia e democracia.

Entre os conteúdos conceituais (fatos, conceitos e princípios) estão os conhecimentos do campo das Ciências Naturais e Sociais. Correspondem aos conhecimentos curriculares indicados, por exemplo, pelos Parâmetros Curriculares Nacionais (PCN) e pelo Conselho Nacional de Educação (CNE) em suas diretrizes e normativas (BRASIL, 1997; 2010).

Já os conteúdos procedimentais estão associados ao desenvolvimento das habilidades sociais e comunicativas, que constituem a base das relações interpessoais. Saber comunicarse, relacionar-se, partilhar informações (próprias ou não) e dialogar são habilidades fundamentais para os processos de individuação e socialização. Somam-se a esses conteúdos, saber analisar criticamente as informações, interpretando-as e dando a elas novos significados. Para tanto, estar disposto a aprender, a reconsiderar ideias e opiniões prévias, a constantemente ressignificar (aprender a aprender), e saber aceitar críticas, torna-se fundamental.

Saber respeitar e valorizar o mundo subjetivo do outro, saber conviver com a diversidade de perspectivas, com as diferenças e com a existência de interpretações múltiplas, também fazem parte desses componentes procedimentais. De igual modo, saber analisar os valores que regem nossas próprias ações para com os elementos constituintes do meio ambiente e cooperar para a construção do mundo subjetivo alheio, estão inclusos nessa categoria de conteúdo.

Por fim, entre os conteúdos atitudinais estão: o respeito pela individualidade e pela diferença, a cooperação, a autonomia e a democracia. São valores que, ao direcionarem determinadas normas, contribuem para o desenvolvimento de atitudes correspondentes.

Todavia, esses elementos constituintes da competência ambiental não se desenvolvem espontaneamente na esfera educativa. Prescindem de um contexto onde o ambiente de aula, as decisões organizativas, as normas de conduta e os papeis que se atribuem aos sujeitos do 
processo educativo, correspondam aos valores que se quer ensinar (ZABALA, 1998); ou seja, necessitam de um contexto de Aprendizagem Cooperativa (AC).

\section{As interações sociais, os pressupostos da AC e as dimensões da prática educativa}

Um dos desafios para aqueles que se dedicam à EA é buscar mecanismos para que os sujeitos desenvolvam uma compreensão mais ampla do próprio meio ambiente, no qual novos centros de interesses e significados possam emergir. Uma das maneiras de favorecermos essa ampliação está nas interações sociais, em especial, naquelas que ocorrem no contexto educativo.

Ao considerarmos que a escola possibilita o intercâmbio de conhecimentos, experiências, visões de mundo, atitudes e valores diversos, podemos afirmar que a educação é uma prática social que atua na configuração da existência humana individual e grupal (LIBÂNEO, 2010). Ela se dá na interlocução dos diferentes saberes que estão sempre em reconstrução e tem o diálogo como elemento fundamental.

Nesse sentido, a comunicação transforma-se em um horizonte linguístico que somente se ressignifica no encontro com o horizonte de outro alguém. Isso porque, o homem não reage simplesmente à estímulos do contexto onde está inserido, mas atribui sentido às suas ações. Por meio das funções cognitiva, expressiva e comunicativa da linguagem é capaz de comunicar percepções, desejos, intenções, expectativas e pensamentos (BANNELL, 2006).

Se é nas relações que reconhecemos os conflitos e os problemas, onde há potência para superá-los, o ambiente educativo deve ser transformado num espaço comunicacional de participação, de aprendizagem, de debate, de reflexão e de difusão de informações (COLL; COLOMINA, 1996; GUIMARÃES, 2010). Para tanto, é imprescindível analisarmos que tipo de estrutura de aprendizagem é capaz de potencializar a socialização, já que as relações entre os estudantes incidem, de forma decisiva, sobre a aquisição de conteúdos conceituais, competências e destrezas sociais, sobre o grau de adaptação às normas estabelecidas, sobre a superação do egocentrismo e a relativização progressiva do ponto de vista próprio.

Guimarães (2005) sugere que uma intervenção educacional adequada deva se fundamentar em uma abordagem relacional onde as ações pedagógicas favoreçam um ambiente educativo de conscientização. Em outras palavras, um ambiente cooperativo que potencialize transformações individuais e coletivas; um espaço no qual ocorra a reconstrução dos laços sociais, o reconhecimento e a identificação cultural dos indivíduos (FRANTZ, 2001). E é aqui que destacamos a Aprendizagem Cooperativa.

A AC é entendida, formalmente, como um método ou estratégia de ensino baseada na interação social que consiste na utilização de pequenos grupos, de tal modo que seus membros trabalhem em conjunto para maximizarem sua própria aprendizagem e a dos demais colegas. É um trabalho em grupo estruturado para que todos os alunos interajam, troquem informações e possam ser avaliados de forma individual pelo seu trabalho (JOHNSON; JOHNSON; HOLUBEC, 1999; SLAVIN, 1999; LOPES; SILVA, 2009).

Embora seja comum organizarmos grupos em nossas aulas, disciplinas e/ou práticas de EA, há um modus operandi específico que caracteriza o trabalho em grupos cooperativos. Há uma estrutura de aprendizagem própria, ou seja, um conjunto de elementos que intervém, de maneira inter-relacionada, no processo de ensino e de aprendizagem (JOHNSON; JOHNSON; HOLUBEC, 1999; MASSET, 2004).

Um Grupo de Aprendizagem Cooperativa (GAC) é aquele onde os estudantes sabem que seus rendimentos dependem do esforço de todos os membros da equipe. Nessa organização, "o grupo é mais do que a soma de suas partes, e todos os alunos tem um melhor desempenho do que se tivessem trabalhado sozinhos" (JOHNSON; JOHNSON; HOLUBEC, 1999, p.7). Baseia-se numa estrutura de aprendizagem cooperativa caracterizada por uma 
interdependência de finalidades específica, diferente das modalidades individualista e competitiva.

Em uma organização da classe na qual cada aluno faz algo sem importar-se com o que fazem seus companheiros não há interdependência de finalidade, pois conseguir seu objetivo independe se os demais conseguirão. Nesse caso, temos uma estrutura individualista, onde o professor se dirige por igual a todos os alunos e resolve, individualmente, as dúvidas ou os problemas que surgem. O trabalho é individual, mas não competitivo, cada um trabalha em seu espaço e não importa o que fazem os demais (MASSET, 2004).

Quando se estabelece uma espécie de rivalidade entre os alunos para ver quem aprende mais, melhor e mais depressa, dizemos que há uma interdependência de finalidades negativa. Alguém consegue seu objetivo se, e somente se, os demais não alcançarem suas metas. Trata-se de uma estrutura de aprendizagem competitiva, onde a ajuda mútua entre os alunos não tem sentido, pois se alguém ensina algo a um companheiro este pode superá-lo. Nessa perspectiva, cada aluno deve ser o único responsável por sua aprendizagem (SLAVIN, 1999; LOPES; SILVA, 2009).

Essa estrutura de aprendizagem, juntamente com a anterior, pouco contribui e/ou contribui negativamente para o desenvolvimento dos elementos constituintes da competência ambiental. Afinal, como promover a cooperação mútua e equitativa nos processos de decisão, valorizar as diferentes formas de conhecimento e respeitar as diferenças tendo como princípio essas configurações?

Por outro lado, se os estudantes se ajudam para aprender cada vez mais, há o que se pode denominar de interdependência de finalidades positiva. Refere-se à sensação de que se está dependente do outro de modo que não se consegue ser bem-sucedido a não ser que os demais sejam, e vice-versa. O trabalho em grupo é visto como uma forma de maximizar a aprendizagem de todos os membros e o objetivo torna-se aprender, estando certo de que todos os membros também aprendem. Nessa configuração, um aluno consegue seu objetivo se, e somente se, os demais conseguem também a mesma meta. Logo, o trabalho é individual, pois cada um é responsável por sua aprendizagem, mas ao mesmo tempo cooperativo. A ajuda mútua não apenas se tolera, mas é fomentada; é considerada essencial (LOPES; SILVA, 2009; MASSET, 2001; 2004; REIS, 2011).

Além da interdependência positiva, existem outros quatro elementos-chave para que uma cooperação verdadeira ocorra, sendo assim considerados os pressupostos da AC: responsabilização, interação promotora, processamento de grupo e habilidades sociais (SLAVIN, 1999; JOHNSON; JOHNSON; SMITH, 1998; MASSET, 2004).

A responsabilização ou responsabilidade individual e grupal parte do princípio de que o grupo deve assumir a responsabilidade por alcançar os seus objetivos e de que cada membro será responsável por cumprir com sua parte para o trabalho comum. O desempenho de cada um deve ser avaliado e os resultados transmitidos ao grupo e ao indivíduo para se determinar quem necessita de mais ajuda, apoio e incentivo. Busca-se fazer com que cada membro seja uma pessoa cada vez melhor em suas próprias características, seja em termos de capacidades cognitivas ou em termos de capacidades sociais. Assim, fortalecendo o individual se está também fortalecendo o coletivo (JOHNSON; JOHNSON; SMITH, 1998; LOPES; SILVA, 2009).

Por meio da interação promotora ou face a face assegura-se que os estudantes promovam o sucesso uns dos outros, encorajando, ajudando, dando assistência e valorizando os esforços de cada um para aprender e, também, que interajam com os colegas de modo a explicar, elaborar e relacionar os conteúdos ensinados. Fazer isso propicia o desenvolvimento de processos cognitivos e permite com que os membros do grupo estimulem cada um a raciocinar e tirar conclusões próprias. Assim, os elementos do grupo apoiam-se e se auxiliam; trocam informações e materiais; comentam e avaliam o trabalho uns dos outros; discutem as 
conclusões e os raciocínios dos colegas; geram confiança e trabalham para o bem comum (REIS, 2011).

O processamento de grupo ou a avaliação de grupo diz respeito à identificação dos meios para melhorar os processos que os membros vêm usando para maximizar seu próprio aprendizado e o aprendizado mútuo. Permite determinar as ações que são positivas e as que são negativas, quais condutas manter e quais modificar e como aumentar a eficácia da equipe. Isso favorece com que os membros se concentrem na preservação do grupo, com que tenham um feedback de sua participação, enfatizando a ideia de que sempre é possível melhorar (JOHNSON; JOHNSON; SMITH, 1998).

Já as habilidades sociais referem-se às competências interpessoais e grupais que devem ser ensinadas e estimuladas, assegurando de que estão sendo utilizadas adequadamente. Dentre elas, podemos citar: partilhar os materiais, pedir ajuda, encorajar os outros a se comunicarem de forma clara, aceitar as diferenças, escutar ativamente, resolver conflitos, partilhar ideias, celebrar o sucesso, ser paciente, ajudar os outros e tomar decisões (LOPES; SILVA, 2009; MASSET, 2004; REIS, 2011).

A adoção de uma estrutura cooperativa e a opção por se trabalhar com GAC deve contemplar, de maneira inter-relacionada e concomitante, esses cinco pressupostos (figura 01). Isso implica dizer que a AC demanda um alto nível de estruturação e se distancia da ideia de uma simples atividade de agrupamento. Embora em sua dinâmica possamos visualizar aspectos das interações educativas do tipo tutoria e do tipo colaboração, sua concretização depende desses elementos-chave.

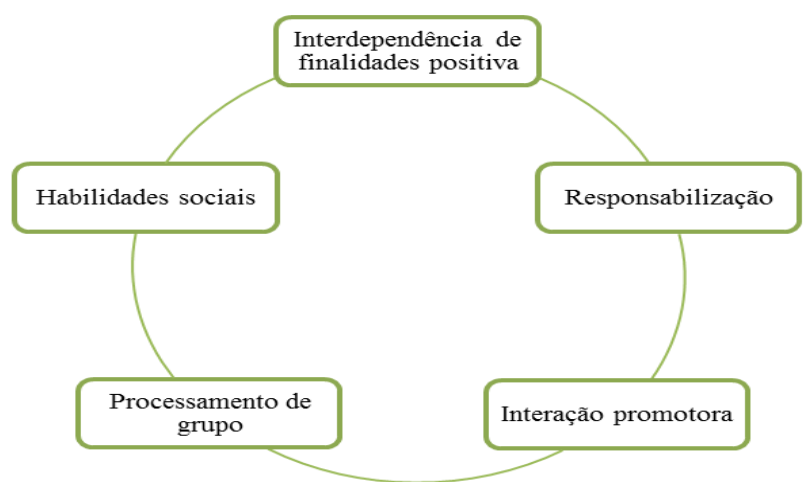

Figura 01 - Pressupostos da Aprendizagem Cooperativa

A tutoria seria uma relação entre dois alunos que, diante de um problema específico, apresentam um nível distinto de habilidade, e onde há diferenças nas responsabilidades e na reciprocidade das transações comunicativas. Já a colaboração é centrada na aquisição e/ou na aplicação de um conhecimento entre dois ou mais alunos com habilidades similares que se organizam em grupos homogêneos, onde a igualdade e a reciprocidade são elevadas ${ }^{3}$.

Além desses pressupostos, a AC fundamenta-se, também, na teoria cognitivoevolutiva, que vê a cooperação como um pré-requisito para o crescimento cognitivo (SLAVIN, 1999). Essa perspectiva baseia-se nas formulações teóricas construtivistas de Piaget e Vygotsky.

Para o epistemólogo suíço, quando um conflito saudável de pensamentos ocorre criase um desequilíbrio cognitivo que, por sua vez, estimula a habilidade para se posicionar e, ao mesmo tempo, o desenvolvimento. Assim, quando os alunos se confrontam com pontos de

\footnotetext{
${ }^{3}$ Para mais detalhes a respeito da diferença entre os termos tutoria, colaboração e cooperação indicamos os trabalhos de Damon e Phelps (1989) e Monereo e Gisbert (2005).
} 
vista opostos, geram-se incertezas ou conflitos de conceitos, o que cria uma necessidade de reconceitualização e uma busca por novas informações. Consequentemente, o sujeito tende a construir uma conclusão mais refinada e mentalmente profunda por meio de reestruturações intelectuais (COLL, 1984; JOHNSON; JOHNSON; SMITH, 1998).

Ao discutir as influências da interação social sobre o desenvolvimento da inteligência, Piaget discorre sobre a existência de dois tipos de relações: a coação e a cooperação. A primeira corresponderia a um nível baixo de socialização, caracterizado pela autoridade, onde um fala e o outro limita-se a ouvir e a memorizar. Já a cooperação permite o desenvolvimento das operações mentais. Nela não há assimetria ou imposição, mas, sim, discussões, trocas de pontos de vista e controle mútuo dos argumentos; representaria, então, o mais alto nível de socialização (LA TAILLE, 1992).

Por sua vez, as contribuições vygotskyanas estão na ideia de que os esforços cooperativos para se aprender, entender e resolver problemas são essenciais para se construir o conhecimento e transformar perspectivas conjuntas em funcionamento mental interno. A execução coletiva de tarefas levaria à produções mais elaboradas, isso porque a interação social seria a origem e o motor da aprendizagem e do desenvolvimento intelectual, que se dá com o processo de regulação interpsicológica (fazer ou conhecer com a ajuda do outro) e intrapsicológica (fazer ou conhecer por si mesmo) (COLL, 1984; JOHNSON; JOHNSON; SMITH, 1998).

Para ambos, Piaget e Vygotsky, "trabalhar de modo cooperativo com parceiros e instrutores mais capazes resulta em desenvolvimento cognitivo e em crescimento intelectual" (JOHNSON; JOHNSON; SMITH, 1998, p.29, tradução nossa). Logo, a aprendizagem é potencializada quando indivíduos com opiniões divergentes entram em controvérsia e chegam a uma nova significação ou a uma síntese.

É essa perspectiva de aprendizagem que fundamenta a dimensão psicológica da AC, e que influencia as demais dimensões da prática pedagógica (didática, epistemológica e sociológica). Segundo Zabala (1998), existem instrumentos teóricos de diferentes naturezas que nos permitem pensar sobre a maneira de atuarmos e intervirmos nos processos de ensino e de aprendizagem. Esses instrumentos representam as quatro dimensões da prática educativa, que estão estritamente inter-relacionadas. Compreender uma delas, requer considerar as demais.

Diferentemente de muitas ações pedagógicas que destacam somente a importância da relação professor-aluno para o alcance de objetivos educativos, a AC defende que as relações que se estabelecem entre os alunos não devem ser vistas como tendo uma influência secundária. Valoriza as interações estudantis que incidem, de forma decisiva, sobre o processo de socialização, sobre a aquisição de competências e sobre o rendimento escolar (COLL, 1984).

Com isso, a atividade docente adquire novo enfoque: o papel do professor passa a ser organizacional, tendo que articular e facilitar a aprendizagem em equipe. Suas funções tornam-se múltiplas e cabe a ele tomar uma série de decisões prévias, explicar aos alunos a tarefa de aprendizagem e os procedimentos de cooperação, supervisionar os trabalhos nas equipes, avaliar o nível de aprendizagem dos alunos, atentar-se com que eficácia estão funcionando os grupos e colocar em funcionamento os elementos-chave da AC (JOHNSON, JOHNSON; HOLUBEC, 1999).

Deve ajudar os membros do GAC a utilizar e a construir sobre as ideias dos demais passando a valorizá-las. Nesse sentido, o docente torna-se coprotagonista do processo de aprendizagem, assumindo a responsabilidade de planejar, implementar e avaliar, ajudar os estudantes a se expressarem, a se comunicarem, a negociar significados, a tomar decisões e a resolver problemas. São esses elementos que caracterizam a dimensão didática da AC. 
Essa dimensão diz respeito à questão de como ensinar, uma vez que há sempre uma maneira mais ou menos adequada, mais ou menos eficaz, de configurar as situações de ensino e de aprendizagem. Ela está atrelada à afirmação de que "por trás de qualquer proposta metodológica se escondem [...] certas ideias mais ou menos formalizadas e explícitas em relação aos processos de ensinar e aprender" (ZABALA, 1998, p.27).

Em relação à dimensão epistemológica - que diz respeito às capacidades que se pretende desenvolver e aos conteúdos que serão ensinados e aprendidos - na AC todas as tipologias de conteúdos tornam-se objetos de ensino. Trabalhar e aprender com outras pessoas de diferentes características requer um conjunto complexo de capacidades de relacionamento (interpessoais e comunicativas). Tais capacidades são aprendidas e praticadas de forma explícita, pois a interação se torna algo oficial. Consequentemente, o trabalho em grupo não é visto apenas como um método ou recurso, mas, também, como um conteúdo (SLAVIN, 1999; MASSET, 2008; REIS, 2000).

Em termos de conteúdos atitudinais a AC possibilita a valorização pessoal, o aumento do interesse e a motivação, além de promover o desenvolvimento de uma comunicação mais eficaz. Produz benefícios em uma ampla gama de situações afetivas e interpessoais ao valorizar, explicitamente, o ensino e a aprendizagem desses conteúdos.

Por fim, podemos dizer que ao fazermos uso da $\mathrm{AC}$ como prática educativa também estamos adotando uma postura ideológica muito clara: a de que a educação tem como função primordial preparar os estudantes para a vida democrática, para ações cooperativas e para o trabalho coletivo. Assim, sua dimensão sociológica ou socioantropológica, que se refere aos propósitos, aos objetivos gerais e às finalidades educativas, contempla a solidariedade, o respeito pessoal e acadêmico, o desenvolvimento do espírito de grupo e a coesão grupal.

Acreditamos que essas quatro dimensões da AC (quadro 03) favoreçam uma ação consistente e de acordo com os preceitos defendidos pelos diversos paradigmas teóricometodológicos da Educação Ambiental, e é por isso que a defendemos e a propomos como prática educativa.

Quadro 03 - Caracterização das dimensões constituintes da Aprendizagem Cooperativa

\begin{tabular}{|l|l|}
\hline $\begin{array}{l}\text { Dimensão sociológica } \\
\text { (Quais são as finalidades educativas?) }\end{array}$ & $\begin{array}{l}\text { Desenvolvimento integral do sujeito (social, psicológico } \\
\text { e cognitivo) e promoção da cidadania. }\end{array}$ \\
\hline $\begin{array}{l}\text { Dimensão epistemológica } \\
\text { (O que se deve ensinar e aprender?) }\end{array}$ & $\begin{array}{l}\text { Conteúdos conceituais (fatos e conceitos), } \\
\text { procedimentais (habilidades sociais) e atitudinais } \\
\text { (valores, atitudes e normas). }\end{array}$ \\
\hline $\begin{array}{l}\text { Dimensão didática } \\
\text { (Como se deve ensinar?) }\end{array}$ & $\begin{array}{l}\text { Grupos de aprendizagem cooperativa (GAC). } \\
\begin{array}{l}\text { Dimensão psicológica } \\
\text { (Como ocorre a aquisição } \\
\text { conhecimento?) }\end{array}\end{array} \quad$ de
\end{tabular}

\section{A AC como prática pedagógica}

O fato de não explicitarmos a constituição das dimensões que compõem nossa prática docente como professores e/ou educadores ambientais, não quer dizer que elas não existam. Mesmos quando não estão claras para nós, optamos por elementos e posturas que determinam nossa intervenção. A adoção de determinada proposta didática será influenciada, por exemplo, pela organização social preconizada, pelas relações interativas estabelecidas, pela forma como ocorre a distribuição do tempo e do espaço, e pela utilização de determinados recursos. 
Dividir os alunos em grupos e lhes pedir que trabalhem juntos não resulta, por si só, em esforços cooperativos. Muitas vezes, essa ação pode levar a uma "competição com mais proximidade", reafirmando posições individualistas (JOHNSON; JOHNSON; SMITH, 1998). Trabalhar com GAC não é somente organizar os alunos à volta de uma mesa para falarem uns com os outros enquanto fazem seus trabalhos individuais, tampouco colocá-los para fazerem tarefas particulares com instruções para que os que terminarem primeiro ajudem os colegas atrasados.

Também não consiste em atribuir uma tarefa a um grupo onde um aluno faz todo o trabalho e os demais escrevem o nome. A cooperação é mais do que estar fisicamente perto dos colegas, discutir a matéria uns com os outros, ajudar ou partilhar materiais. A AC pressupõe, na realidade, uma mudança na estrutura organizativa que afeta todos os aspectos da vida em sala de aula (COLL; COLOMINA, 1996; JOHNSON; JOHNSON; HOLUBEC, 1999; MONEREO; GISBERT, 2005). Trata-se de um esquema de organização que implica repensar e reestruturar toda a atuação docente, e não pode ser entendida apenas como uma mera atividade ocasional ou método.

Nesse sentido, é desejável convertê-la na corrente dominante da prática escolar, pois trata-se de uma via de pensamento filosófico, ético e pedagógico para ensinar a todos e, sobretudo, ensinar uma nova forma de viver (SLAVIN, 1999; MASSET, 2004). Sua implementação envolve a explicitação dos objetivos educacionais, a distribuição dos alunos por grupos adequados de aprendizagem, a explicação das tarefas pretendidas e dos métodos que deverão ser utilizados, o apoio e acompanhamento do progresso dos grupos, a avaliação do desempenho dos alunos, a autorregulação e muitos outros elementos (REIS, 2011).

Isso implica considerar a AC como prática educativa, uma prática pedagógica dotada de características próprias que configura, coerentemente, as dimensões sociológica, epistemológica, psicológica e didática, bem como as variáveis intervenientes da ação docente (sequência de atividades, relações/situações comunicativas, organização social, tempo e espaço, organização dos conteúdos, recursos didáticos e avaliação). Em outras palavras, uma "filosofia que responde a muchas de las necesidades del mundo global en el que vivimos" (LARA, 2001, p.99, grifos da autora).

Pressupõe a ideia de que, se pessoas diferentes são capazes de aprender juntas em uma mesma classe, aprenderão, também, a serem melhores cidadãs fora dela. Esse modo de aprender a trabalhar ensina não apenas interagir com pessoas que pensam diferente em um âmbito local, mas também global.

$\mathrm{Na} \mathrm{AC}$ a linguagem e o diálogo são tidos como instrumentos fundamentais por: (1) estimularem o compartilhamento de ideias e a elaboração de pensamentos mais elaborados; (2) possibilitarem uma perda progressiva do egocentrismo; (3) favorecerem a ajuda mútua, pois tornam a sala de aula um espaço onde os estudantes podem debater e complementar as ideias dos colegas; e (4) contribuírem para o desenvolvimento de capacidades de análise, síntese e reflexões pessoais e coletivas.

Desse modo, podemos dizer que a adoção da AC como prática educativa contribui para: o desenvolvimento do sentimento do nós, por meio do fortalecimento do espírito de grupo; a atitude de escutar de modo compreensivo; a substituição da competição e do individualismo pela cooperação; o estímulo à iniciativa, à autonomia e à criatividade, devido ao empenho do grupo e de seus membros em elaborar conhecimento, ao invés de simplesmente recebê-lo; a circulação de informes, ideias e sugestões que estimulam novos pensamentos para a superação de obstáculos ou solução de problemas; o enriquecimento intelectual, pois uma mesma questão pode ser apreciada de diversos ângulos; a valorização da heterogeneidade e da diversidade; o desenvolvimento da responsabilidade individual e coletiva; o senso de democracia e o favorecimento da aprendizagem. 
Cooperação e educação podem ser consideradas, portanto, duas práticas sociais que se processam, de tal forma que uma contém a outra; entrelaçam-se e se potencializam. Na prática cooperativa se produz conhecimento, educação e aprendizagem; na prática educativa, como processo complexo de relações humanas, encontra-se a cooperação. A cooperação torna-se uma ação consciente e combinada entre indivíduos, com vistas a um determinado fim, ou seja, um processo social pautado na interação humana, pelo qual um grupo de pessoas busca encontrar respostas e soluções para seus problemas comuns, bem como realizar objetivos semelhantes por meio de ações coletivas (FRANTZ, 2001).

Uma prática educativa fundamentada na Aprendizagem Cooperativa preconiza e potencializa o processo de interlocução de diferentes vozes que se aproximam e se identificam para a construção de espaços comuns de atuação, sem, no entanto, renunciarem a si mesmas. Essas vozes preservam, assim, as condições e as posições do diálogo de seus saberes, de suas experiências de vida. Na argumentação em favor do entendimento comum, por meio da linguagem simbólica, os sujeitos configuram-se e se educam para a própria cooperação (FRANTZ, 2001).

Nessa perspectiva, o trabalho cooperativo torna-se instrumento fundamental para a promoção de atitudes e valores, bem como, para o conflito externo de sentidos, visões de mundo e conhecimentos divergentes que, posteriormente, gerarão novas ressignificações. Conhecer e experienciar mundos particulares, por meio de um diálogo de saberes, são também aspectos essenciais para a ampliação do meio ambiente individual dos sujeitos envolvidos nesse processo.

Ao defendermos a AC como prática educativa na EA estamos, tal como Guimarães (2010), opondo-nos a uma educação meramente teórica e informativa, que coloca o professor como transmissor de conhecimentos e o aluno como receptor dessas informações tidas como verdades absolutas; uma educação que não estimula a interação entre os indivíduos e que reforça valores fragmentários e individualistas. Afinal,

Se a criança cresce cada vez mais egoísta, e, se ao tomar as suas decisões, não considera devidamente os fatos conhecidos e com eles relacionados, então alguma coisa está errada. Ela não estará utilizando as oportunidades com proveito. Talvez não a tenhamos auxiliado suficientemente. Talvez o tenhamos feito, mas não como o devêramos (KILPATRICK, 1973, p.88).

\section{Algumas considerações}

Ao apresentarmos os conhecimentos requeridos pela concepção de educação atual e aproximá-los dos objetivos defendidos pelas diferentes perspectivas de EA, buscamos destacar uma preocupação prevalente: a de se favorecer o ensino e a aprendizagem de conteúdos, o desenvolvimento de procedimentos, atitudes e valores fundamentais para a melhoria de nossa sociedade.

Essa melhoria depende do processo educacional que, por sua vez, é influenciado pelas nossas ações pedagógicas como professores e/ou educadores ambientais - o que não significa dizer que estamos desconsiderando as demais variáveis que interferem no trabalho escolar, apenas estabelecemos, neste artigo, a prática docente como objeto de análise. Essas ações são direcionadas pela prática educativa que adotamos e pelo significado que damos às suas dimensões. Mudanças na estrutura de aprendizagem e, consequentemente, nas variáveis intervenientes são necessárias para concretizarmos o desenvolvimento dos elementos constituintes da competência ambiental.

Embora as pesquisas sobre o uso da AC tenham ocorrido mais intensamente entre os anos de 1970-80 - com os trabalhos dos irmãos David e Roger Johnson do Centro de Aprendizagem Cooperativa da Universidade de Minesota; com os estudos de Shlomo Sharan 
e Yael Sharan na Universidade de Tel Aviv; com as pesquisas de Elliott Aronson da Universidade de Santa Cruz, na Califórnia, EUA; com os trabalhos de Robert Slavin e Nancy Madden da Universidade Johns Hopkins e com as investigações de Spencer Kagan da Universidade da Califórnia, também nos Estados Unidos - ainda hoje, a AC é investigada e utilizada em instituições escolares de muitos países, como Suíça, Israel, Canadá, Austrália, Estados Unidos, Portugal e Espanha (JOHNSON; JOHNSON; SMITH, 1998; MASSET, 2004; LOPES; SILVA, 2009; REIS, 2011).

Entretanto, essas pesquisas ainda são pouco divulgadas e conhecidas no contexto nacional. Em comparação com a literatura estrangeira, são escassos os trabalhos brasileiros sobre a AC (CARVALHO, 2000, 2013; BARBOSA; JÓFILI, 2004; LIMA, 2012; TEODORO, 2011; LEITE et al., 2013; CAPELLINI; BELLO, 2014) e não há nenhum estudo que discuta sua potencialidade como prática educativa no contexto ambiental, tal como aqui fazemos.

Neste trabalho, queremos destacar que, para se alcançar o objetivo de formar cidadãos participativos não dá para seguirmos, apenas, com as aulas magistrais como método pedagógico. Torna-se necessário buscarmos e utilizarmos mecanismos que promovam interação entre os alunos, integração social, capacidade de se comunicarem efetivamente e de colaborar. A tomada de decisão, a construção de confiança, a comunicação e as habilidades para administrar conflitos são, também, conteúdos que devem ser ensinados.

O modelo educacional predominante (individualista e competitivo) prioriza a elaboração de conceitos, relações e significados individuais, entretanto, os processos de análise e síntese que resultam em novas reflexões não ocorrem somente na esfera particular. Esses processos ocorrem por meio do conflito externo de sentidos, visões de mundo e conhecimentos divergentes que, posteriormente, irão gerar novas ressignificações.

A AC como prática educativa ambiental, é um caminho potencial para a promoção de atitudes e valores democráticos, bem como, para o desenvolvimento do conhecimento tido como uma construção social. Conhecer e experienciar mundos particulares, por meio de um diálogo de saberes em grupos cooperativos, são aspectos essenciais para a ampliação do meio ambiente dos sujeitos envolvidos nesse processo.

É por meio da interação interpessoal que se potencializa a ampliação de nosso mundo individual, pois passamos a visualizar elementos que, antes, não tinham visibilidade; é por meio dela que temos contato com outras perspectivas valorativas. Nos espaços coletivos, há sempre a explicitação de julgamentos distintos que possibilitam uma perspectiva nova antes não visível/perceptível; é onde damos ao outro e a nós mesmos a oportunidade de construir mais relações significativas e, assim, elaborar sínteses que ampliem as experiências e os conhecimentos.

\section{Referências}

ALARCÃO, I. Professores reflexivos em uma escola reflexiva. 5aed. São Paulo: Cortez, 2007.

ALVAREZ, A.; DEL RÍO, P. Cenários educativos e atividade: uma proposta integradora para o estudo e projeto do contexto escolar. In COLL, C.; PALACIOS, J.; MARCHESI, A. (Orgs.). Desenvolvimento psicológico e educação: psicologia da educação. Porto Alegre: Artmed, 1996. Vol. 2, p.201-221.

BANNELL, R. I. Habermas e a Educação. Belo Horizonte: Autêntica, 2006.

BARBOSA, R. M. N.; JÓFILI, Z. M. S. Aprendizagem cooperativa e ensino de Química: parceria que dá certo. Ciência \& Educação, Bauru-SP, v.10, n.1, p.55-61, 2004. 
BRASIL. Parâmetros Curriculares Nacionais: introdução aos parâmetros curriculares nacionais. Secretaria de Educação Fundamental. Brasília: MEC/SEF, 1997.

BRASIL. Lei nº.795 de 27 de abril de 1999. Dispõe sobre a educação ambiental, institui a Política Nacional de Educação Ambiental e dá outras providências. Diário Oficial [da República Federativa do Brasil], Brasília, DF, 28 abr. 1999. Disponível em <http://www.planalto.gov.br/ccivil_03/leis/19795.htm>. Acesso em 14 jan. 2012.

BRASIL. Conselho Nacional de Educação (CNE). Resolução n. ${ }^{\circ}$ 4, de 13 de Julho de 2010. Define Diretrizes Curriculares Nacionais Gerais para a Educação Básica. Diário Oficial da União, Brasília, 14 de julho de 2010, Seção 1, p. 824.

CAPELLINI, V. L. M. F.; BELLO, M. M. S. Aprendizagem cooperativa: estratégia pedagógica inclusiva na educação básica. In KOBAYASHI, M. do C. M.; PIROLA, N. A.; ROSSI, F. (Orgs.). Cadernos de docência na educação básica III. $1^{a}$ ed. São Paulo: Cultura Acadêmica, 2014. v. 1, p. 8393.

CARVALHO, F. V. Pedagogia da cooperação: uma introdução à metodologia da aprendizagem cooperativa. São Paulo: Imprensa Universitária Adventista, 2000.

CARVALHO, F. V. Estratégias e recursos de ensino através da Aprendizagem Cooperativa aplicados aos graduandos da Licenciatura em Ciências Biológicas. Scientia Vitae, São Roque-SP, v.1, n.1, p. 6277, Jun. 2013.

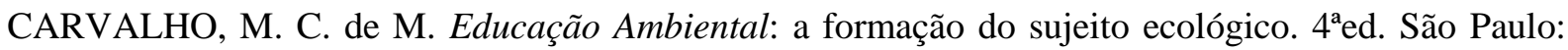
Cortez, 2008.

COLL, C. Estructura grupal, interacción entre alumnos y aprendizaje escolar. Infancia y Aprendizaje: Journal for the Study of Education and Development, Madrid, n.27-28, p. 119-138, 1984.

COLL, C.; COLOMINA, R. Interação entre alunos e aprendizagem escolar. In COLL, C.; PALACIOS, J.; MARCHESI, A. (Orgs.). Desenvolvimento psicológico e educação: psicologia da educação. Porto Alegre: Artmed, 1996. Vol. 2, p.298-314.

COLL, C.; POZO, J. I.; SARABIA, B.; VALLS, E. Os conteúdos na reforma: ensino e aprendizagem de conceitos, procedimentos e atitudes. Tradução de Beatriz Affonso Neves. Porto Alegre: Artes Médicas, 2000.

DAMON, W.; PHELPS, E. Critical distinctions among three approaches to peer education. International Journal of Educational Research, Belfast - Northern Ireland, v.13, n.1, p. 9-19, 1989.

DELORS, J. et al., Educação: um tesouro a descobrir. Relatório para a UNESCO da Comissão Internacional sobre Educação para o século XXI. Tradução de Guilherme João de Freitas Teixeira. Brasília: Setor de Educação da Representação da UNESCO no Brasil/Fundação Faber Castell, 2010.

FRANTZ, W. Educação e cooperação: práticas que se relacionam. Sociologias, Porto Alegre, ano 3, n.6, p.242-264, jul./dez. 2001.

GUIMARÃES, M. Intervenção educacional: do "de grão em grão a galinha enche o papo" ao "tudo junto ao mesmo tempo agora". In Encontros e Caminhos: formação de educadoras(es) ambientais e coletivos educadores. Brasília: MMA, 2005. p.189-200.

GUIMARÃES, M. A formação de educadores ambientais. $5^{\text {a }}$ ed. Campinas: Papirus, 2010. (Coleção Papirus Educação). 
IMBERNÓN, F. Pedagogia Freinet: a atualidade das invariantes pedagógicas. Tradução de Alexandre Salvaterra. Porto Alegre: Penso, 2012.

JOHNSON, D. W.; JOHNSON, R. T.; HOLUBEC, E. J. El aprendizaje cooperativo en el aula. Tradução de Gloria Vitale. Buenos Aires: Paidós, 1999.

JOHNSON, D. W.; JOHNSON, R. T.; SMITH, K. A. Cooperative Learning Returns To College: What Evidence Is There That It Works? Change - The Magazine of Higher Learning. Philadelphia, p. 27-35, jul./ago, 1998.

KILPATRICK, W.H. Educação para uma civilização em mudança. Tradução de Noemy S. Rudolfer. $11^{a}$ ed. São Paulo: Melhoramentos, 1973.

KRASILCHIK, M. Reformas e realidades: o caso do ensino de ciências. São Paulo em perspectiva, São Paulo, v.14, n.1, p.85-93, 2000.

LA TAILLE, Y. O lugar da interação social na concepção de Jean Piaget. In ; OLIVEIRA, M. K.; DANTAS, H. (Orgs.). Teorias psicogenéticas em discussão. 8a ed. São Paulo: Summus, 1992. p.11-21.

LARA, S. Una estrategia eficaz para fomentar la cooperación. ESE - Estudios Sobre Educación, Navarra - Espanha, n.1, p.99-110, 2001.

LEITE, I. S.; LOURENÇO, A. B.; LICIO, J. G.; HERNANDES, A. C. Uso do método cooperativo de aprendizagem Jigsaw adaptado ao ensino de nanociência e nanotecnologia. Rev. Bras. Ensino Fís., São Paulo, v.35, n.4, p.1-7, dez., 2013.

LIBÂNEO, J. C. Pedagogia e pedagogos, para quê? 12ª ed. São Paulo: Cortez, 2010.

LIMA, S. J. de. Aprendizagem Cooperativa: um experimento no ensino de contabilidade. 2013. 244f. Dissertação (Mestrado em Ciências) - Universidade de São Paulo/Programa de Pós-graduação em Controladoria e Contabilidade. Faculdade Economia, Administração e Contabilidade, São Paulo, 2012.

LOPES, J.; SILVA, H. S. A Aprendizagem Cooperativa na sala de aula: um guia prático para o professor. Lisboa: LIDEL, 2009.

LOUREIRO, C. F. Trajetórias e fundamentos da Educação Ambiental. $3^{\text {a }}$ ed. São Paulo: Cortez, 2009.

MASSET, P. P. Atención a la diversidad y aprendizaje cooperativo en la educación obligatoria. Málaga: Ediciones Aljibe, 2001.

MASSET, P. P. Aprender juntos alunos diferentes: los equipos de aprendizaje cooperativo en el aula. Barcelona: Octaedro, 2004.

MASSET, P. P. El aprendizaje cooperativo como recurso y como contenido. Revista Aula de Innovación Educativa, Barcelona - Espanha, n.170, p.37-41, mar. 2008.

MONEREO, C.; GISBERT, D. D. Tramas: procedimentos para a aprendizagem cooperativa. Tradução de Cláudia Schilling. Porto Alegre: Artmed, 2005.

NÉRICI, I. G. Educação e metodologia. 2aed. São Paulo: Livraria Pioneira Editora, 1970. 
PEDRINI, A. de G.; SAITO, C. H. (Orgs.). Paradigmas metodológicos em Educação Ambiental. Petrópolis: Vozes, 2014.

POZO, J. I.; CRESPO, M. A. G. A aprendizagem e o ensino de ciências: do conhecimento cotidiano ao conhecimento científico. $5^{\text {a }}$ ed. Porto Alegre: Artmed, 2009.

REIGOTA, M. O que é Educação Ambiental? 2a ed. São Paulo: Brasiliense, 2009 (Col. Primeiros passos).

REIS, P. R. A Educação para a cidadania através do desenvolvimento de capacidades de cooperação. Cadernos de Educação de Infância. Lisboa, n.56, p.14-15, out./dez, 2000.

REIS, P. R. A gestão do trabalho em Grupo. Indução e desenvolvimento profissional docente. Aveiro - Portugal: Universidade de Aveiro, 2011. (Coleção Indução e Desenvolvimento Profissional Docente).

SANMARTÍ, N. Didáctica de las ciências en la educación secundaria obligatoria. Madri: Síntesis Educación, 2002.

SAUVÉ, L. Uma cartografia das correntes em educação ambiental. In SATO, M.; CARVALHO, I. C. de M. (Orgs.). Educação Ambiental: pesquisa e desafios. Porto Alegre: Artmed, 2005. p.17-44.

SLAVIN, R. Aprendizaje cooperativo: teoria, investigación y práctica. Tradução de Miguel Wald. Buenos Aires: Aique Grupo Editor S.A., 1999. (Coleção Carrera Docente).

TASSARA, E. T. de O.; ARDANS, O. Intervenção psicossocial: desvendando o sujeito histórico e desvelando os fundamentos da educação ambiental crítica. In Encontros e Caminhos: formação de educadoras(es) ambientais e coletivos educadores. Brasília: MMA, 2005. p.201-216.

TEODORO, D. L. Aprendizagem Cooperativa no Ensino de Química: investigando uma atividade didática elaborada no formato jigsaw. 2011. 120f. Dissertação (Mestrado em Ciências - Química Analítica) - Universidade de São Paulo/Instituto de Química de São Carlos, São Carlos, 2011.

TOZONI-REIS, M. F. C. (Re)Pensando a Educação Ambiental. In: TOZONI-REIS, M. F. de C. Metodologias aplicadas à Educação Ambiental. 2 ed. Curitiba: IESDE Brasil S.A., 2008. p. 7-17.

ZABALA, A. A prática educativa: como ensinar. Porto Alegre: Artmed, 1998.

ZABALA, A.; ARNAU, L. Como aprender e ensinar competências. Porto Alegre: Artmed, 2010.

Versão recebida em: 06/09/2014

Aceite em: 12/05/2016 